\title{
Transparency effects on policy compliance: disclosing how defaults work can enhance their effectiveness
}

\author{
YAVOR PAUNOV* \\ University of Mannheim, Mannheim, Germany \\ MICHAELA W ÄNKE \\ University of Mannheim, Mannheim, Germany \\ TOBIAS VOGEL \\ University of Mannheim, Mannheim, Germany
}

\begin{abstract}
From an ethical standpoint, transparency is an essential requirement in public policy-making. Ideally, policy-makers are transparent and actively disclose the presence, purpose and means of a decision aid. From a practical point of view, however, transparency has been discussed as reducing the effectiveness of decision aids. In the present paper, we elaborate on how transparency affects the effectiveness of defaults. In three experiments, we manipulated whether the endorser was transparent about the default or not and assessed participants' decisions to opt out or comply. Throughout the experiments, we found that proactive transparency reduced opt-out rates as compared to a non-transparent default condition. Moreover, proactive disclosure of a default reduced opt-out rates as compared to informed control groups, where participants imagined they had retrieved the default-related information by themselves (Studies 1 and 2). The results further indicate that a lack of proactive disclosure may lead targets to perceive the endorser as less sincere and to feel deceived, which in turn hinders the effectiveness of the default. In general, our findings lend support to the proactive transparency paradigm in governance and show that a default-based policy can be transparent and effective at the same time.
\end{abstract}

Submitted 22 February 2018; accepted 9 October 2018

\section{Introduction}

Rooted in the popular nudging paradigm, defaulting quickly became a hot discussion topic in both the academic and public domains. Default interventions

\footnotetext{
* Correspondence to: University of Mannheim, Department of Consumer and Economic Psychology, Parkring 47, 68159 Mannheim, Germany. Email: yavor.paunov@gess.uni-mannheim.de
} 
are characterized by a decision situation in which one of the choice options is pre-selected, but the decision-maker retains the possibility to actively choose another alternative (i.e., to opt out). In general, people tend to stick to the preselected option, making defaulting an effective strategy for influencing choice. Defaults are particularly effective in cases when the decision-makers perceive the default option as the recommended one (McKenzie et al., 2006) or when they postpone the decision for a later time (for a comprehensive review, see Willis, 2013).

Default effects are powerful, and default interventions have been successfully applied by various private and governmental institutions as means of increasing policy compliance. Famous examples include the organ donation policy default by Johnson and Goldstein (2003), the automatic enrollment "Save More Tomorrow" program by Benartzi and Thaler (2004) and Allcott and Mullainathan's (2010) energy-saving defaults. The success of defaults in policy-making seems so prominent that their implementation has even been endorsed in an executive order by US president Barack Obama (on 15 September 2015), in which he encouraged "giving particular consideration to the selection and setting of default options" (Sec.1, (b), iii).

The use of defaults, however, has also raised concerns about their transparency. On the one hand, one might conceive of default implementation as crossing the line between choice enhancement and manipulation. The target of a default intervention is unaware of the influence intent and the means by which the behavioral change is pursued (Hansen \& Jespersen, 2013). Therefore, some have argued that decisions made under such non-transparent conditions are not fully autonomous and are thus limiting people's capability of exercising informed choice (Smith et al., 2012). In response, an increase in transparency was recommended (Sunstein, 2015).

On the other hand, researchers have also contemplated a possible trade-off between the degree of transparency of such interventions and their effectiveness. Luc Bovens (2009) also considered decisions influenced by nudges as non-autonomous and speculated that when people became aware of having been influenced in their choice, they would engage in behaviors that are inconsistent with their initial decision. Therefore, he made the theoretical argument that non-transparent nudges, such as defaults, 'work better in the dark' and become increasingly ineffective as transparency is introduced. Hence, one can argue that making default interventions transparent may be detrimental to their effectiveness.

It goes without saying that both ethicality and effectiveness are of crucial importance in policy-making. But are the two really in contention to each other? According to prominent psychological theorizing, people strive for self-determination (Deci, 1975; Ryan \& Deci, 2000) and resent limitations 
to their freedom of choice (Brehm, 1966). In order to reinstall that freedom, they would deliberately resist choosing the default option and would rather endorse options that are not defaulted. Thus, disclosing the influence attempt may easily decrease its impact.

However, predictions in the opposite direction are also viable. As McKenzie et al. (2006) demonstrate, defaults are perceived as a form of implicit recommendation. The pre-selection of an option communicates that the policymaker actually endorses that option. A transparent communicator - one who voluntarily discloses the default - further emphasizes that he or she considers a particular option to be the best one. Doing so, the communicator transforms the implicit recommendation into an explicit one, and can thus give the default a further boost: explicit expert advice is known to have a profound effect on informing people's behavior (e.g., Kinney et al., 1998).

Moreover, a full endorser disclosure might communicate that the endorser does not want to trick the target populace into a certain behavior (i.e., to choose the pre-selected option), but to help people make an informed choice instead. Such disclosure might further account for a positive effect on policy compliance: targets may form the impression that the endorser is honest and trustworthy. Previous research from political science shows that transparency is positively associated with trustworthiness and also affects policy satisfaction (Park \& Blenkinsopp, 2011) and citizen compliance (Tyler, 1990, 1998). Research from social psychology shows that a disclosed intent can be perceived as working against a communicator's interest, which further boosts perceptions of the communicator's credibility and makes his or her appeals more persuasive (Walster et al., 1966). Put together, there is sufficient theoretical argumentation to doubt a negative influence of disclosure and even to assume that a voluntary disclosure by the endorser might actually boost rather than undermine the effect of defaults.

Given that default interventions gained much prominence in policy settings (e.g., Johnson \& Goldstein, 2003; Benartzi \& Thaler, 2004), the empirical evidence on the topic is surprisingly limited. The few existing experimental studies do not support either perspective, but produced mainly null effects (Loewenstein et al., 2015; Steffel et al., 2016; Bruns et al., 2018). For instance, Loewenstein and colleagues (2015) asked participants to make a hypothetical end-of-life decision (a choice of either prolonging life at all costs or a set of comforting measures, ensuring a smooth end-of life passage). One or the other alternative was defaulted between subjects. Orthogonal to the variation of the default, the researchers varied whether participants were informed of the default before or after making the decision. To isolate default and transparency effects, all participants were asked to make the same decision again, this time imagining the default had not been previously present. The results indicated no 
significant effect of transparency on the participants' choice. As the authors state, however, the finding may possibly reflect carry-over effects stemming from participants' desire for decision consistency (Falk \& Zimmerman, 2013). Yet, in a set of studies, Steffel and colleagues (2016) did not find significant effects of transparency in several defaults either. Importantly for the present analysis, one of their studies actually resembled an institutional policy setting (study 1a). The participants had to imagine they were about to join a fictitious social network that defaulted them to either share their personal details or not. In some conditions, participants received information about the default's purpose and behavioral means. Notably, however, the information was provided in such a way that it was not clear whether the research participants attributed its disclosure to the policy endorser (i.e., the social network), thus representing proactive transparency, or to the experimenters.

With opposing theoretical predictions and scarce empirical evidence, we believe that the effect of transparency on default effectiveness is worth exploring. More specifically, research in a policy setting can benefit from a direct comparison between an uninformed control and an explicit endorser disclosure condition. For the purposes of the present research, we define default transparency as an objective policy characteristic stemming from a full endorser disclosure of the default's presence, purpose and behavioral means.

Lastly, we believe that prior designs leave the role of non-disclosure partially unexplored. In reality, lack of disclosure does not mean that the decisionmakers remain oblivious to the intervention's presence or purpose. When information is not readily available, people remain capable of retrieving it and drawing an inference to reach a decision. Therefore, we first tested the effects of transparency and non-disclosure in a hypothetical scenario that also included a condition in which the participants imagined they had retrieved the default-related information by themselves. Finally, a third study tested the effect of transparency versus non-disclosure on compliance for actual choices.

\section{Study 1}

The first study compared the default option opt-out rate following full endorser disclosure with an uninformed control group. A second control condition was run in which the participants received the same information as in the transparent condition, but imagined they had retrieved it by themselves (awareness condition). This setting enabled us to control for the amount of presented information, keeping it equivalent to the transparent condition.

Given people's tendency to strive for self-determination (Deci \& Ryan, 2000), one would predict higher opt-out rates in both the transparent condition and the awareness condition compared to the uninformed control 
group. In fact, defaults may be viewed as particularly paternalistic if endorsers reveal their intent.

Alternatively, a communication perspective holds that transparency evokes inferences about the endorser as fair and trustworthy. Such a conception would predict lower opt-out rates in the transparent condition compared to the two non-disclosure conditions. Both accounts point to the subjective feeling of trusting the endorser versus suspecting the endorser of manipulation. Therefore, we measured the extent to which participants perceived the endorser as trustworthy.

\section{Method}

\section{Participants and design}

The required sample size for a planned power of $80 \%$ (two-tailed, $\alpha=0.05$, $\operatorname{Pr}(\mathrm{Y}=1 \mid \mathrm{X}=1) \mathrm{H} 0=0.5$ ) was calculated with $\mathrm{G}^{*}$ Power (Faul et al., 2009) using odds ratios (ORs). With no previous data on the effect of explicit endorser disclosure, we assumed a probability of opt out under transparency $\operatorname{Pr}(\mathrm{Y}=1 \mid \mathrm{X}=1) \mathrm{H} 0=0.33$. This translates into an $\mathrm{OR}$ of 0.492 , rendering the required sample size as 264 participants.

Two-hundred and ninety-two English-speaking participants were recruited via an international online respondent service (210 male, 80 female, 2 unclassified; mean age 33.6 years $(S D=9.6)$ ). Each participant was endowed with US $\$ 0.30$ for participation in the study.

All participants were given a choice scenario where a default was set. Participants were randomly assigned to the following three conditions: a transparent condition where the policy endorser disclosed setting the default in order to influence participants' choices; a control group that received no further information (non-transparent condition); and a control group that received the same information about the default as in the transparent condition, but the participants imagined that they retrieved said information by themselves (non-transparent aware condition).

\section{Stimulus material}

The participants were presented with a hypothetical scenario online. They were asked to imagine that they had recently enrolled in a university. Upon seeing the course program, they noticed that some of their electives had already been pre-selected, but they could change them by filling in a paper form and delivering it to the university administration. In the non-transparent condition, the participants received no further information. In the transparent condition, the university administration notified the participants of the pre-selection. In this condition, the university also explained how defaults are a means of 
influencing people to make a particular choice and that this was the reason why the university pre-selected the electives it wanted the students to choose. In the non-transparent aware condition, the participants were asked to imagine having recently read an article that described how defaults are a means of influencing people to make a particular choice. Based on this article, they would infer that the university wanted them to choose the pre-selected courses. The full text of the scenarios is available in Appendix 1.

\section{Measures}

The main dependent variable was the proportion of people not choosing the default option (opt-out rate), coded 0 for staying with it and 1 for opting out.

In order to measure the feeling of being able to trust the endorser versus feeling manipulated, we used an adapted version of the Trust in Government scale, adapted from Grimmelikhuijsen and Meijer (2012). The questionnaire explores trustworthiness as a multidimensional construct and has three subscales measuring perceived endorser honesty, benevolence and competence. The participants rated their agreement with 15 statements on a five-point Likert scale, ranging from $1=$ 'strongly disagree' to $5=$ 'strongly agree'. Sample items are: "The university administration is professional" (competence), "The university administration is genuinely interested in the students' well-being" (benevolence) and "The university administration approaches students in a sincere way" (honesty). In order to ensure that the participants had read all of the relevant stimulus information, they were asked to briefly describe the scenario in an open format. Finally, the participants were debriefed and thanked in written form.

\section{Results and discussion}

Based on the responses to the control question, we excluded 29 participants for not complying with the instruction (responded with "did not read," "don't know," etc.), 5 for copy-pasting random instruction text and 12 for responding incomprehensibly in a language different from English.

Table 1 shows that the full disclosure by the endorser reduces the opt-out rate in comparison to the two non-transparent conditions. While roughly every second participant chose to opt out in the non-transparent conditions, the opt-out rate dropped to $37.6 \%$ when the endorser was transparent about the default.

To check whether the reduction was significant, we ran a number of binomial logistic regressions. The binary decision $($ stay $=0$; opt out $=1$ ) served as our criterion. This criterion was predicted from two Helmert contrasts. The first Helmert contrast accounted for differences between the non-transparent control conditions (non-transparent $=$ non-transparent aware $=-0.33$ ) and the 
Table 1. Proportion of participants deciding to opt out per condition in Study 1

\begin{tabular}{lccc}
\hline \hline Condition & Transparent & Non-transparent & Non-transparent aware \\
\hline Opt out & $37.6 \%(32 / 85)$ & $51.2 \%(41 / 80)$ & $53.0 \%(43 / 81)$ \\
\hline \hline
\end{tabular}

Note: Participants' opt out to stay with default option ratios are in parentheses.

transparent condition (transparent $=0.67$ ), thus indicating how transparency affects opt-out rates. The second Helmert contrast accounted for differences between the two non-transparent groups (transparent $=0$, non-transparent $=$ -0.50 , non-transparent aware $=0.50)$. It indicates whether mere awareness leads to greater or fewer opt-out decisions as compared to the non-transparent control group.

The analysis yielded the following effects. The first contrast was significant, $\mathrm{b}=-0.726(\mathrm{SE}=0.285)$, Wald $-\chi^{2}(1)=6.487, \mathrm{p}=0.011$. Thus, the participants in the transparent condition were significantly less likely to opt out than those in the non-transparent conditions, in support of the prediction of a positive effect of transparency on policy compliance.

Second, awareness of the default strategy alone did not seem to increase or decrease opt-out rates in comparison to the non-transparent control group, as is evident from the non-significance of the second Helmert contrast, $b=-0.089$ $(\mathrm{SE}=0.338)$, Wald $-\chi^{2}(1)=0.070, \mathrm{p}=0.792$. A summary of the regression coefficients is presented in Table 2 .

As a next step, we explored the role of trustworthiness. When we regressed trustworthiness scores on the same two contrasts, the coefficient for transparency (vs. the other conditions) was not significant, $b=0.117(\mathrm{SE}=0.079), \mathrm{p}=$ 0.138. Accordingly, we did not find any evidence for an indirect effect of disclosure on opt-out decisions via trustworthiness, $b=-0.662$ ( $\mathrm{SE}=0.057), 95 \%$ confidence interval (CI) -0.233 to 0.010 (5000 replicates), although trustworthiness was an independent predictor of opt-out rates, $b=-0.378$ ( $\mathrm{SE}=$ 0.161 ), Wald $-\chi^{2}(1)=5.75, p=0.016$, indicating that the higher the perceived trustworthiness of the endorser, the lower the participant opt-out rates were across conditions.

In summary, the results confirmed the prediction that institutions can increase policy compliance by making default interventions transparent. Notably, the effect appears only when the endorser explicitly discloses the default's presence, purpose and behavioral means. Participants who knew of the possible effect of defaults, but had not been directly informed by the endorser, showed no increase or decrease in compliance. 
Table 2. Summary of logistic regression analysis for the effects of transparency and awareness on opt-out rates

\begin{tabular}{lccccr}
\hline \hline Predictors & $\mathrm{b}$ & $\mathrm{SE}$ & Wald- $\chi^{2}$ & $\mathrm{df}$ & $\mathrm{Exp}(\mathrm{b})$ \\
\hline Transparency & $-0.726^{*}$ & 0.285 & 6.487 & 1 & 0.484 \\
Awareness & -0.089 & 0.338 & 0.070 & 1 & 0.915 \\
Constant & 0.024 & 0.136 & 0.032 & 1 & 1.025 \\
\hline \hline
\end{tabular}

Note: The predictors are Helmert contrast-coded. Transparency compares participants from the transparent condition versus participants from the other two conditions. Awareness compares participants from the non-transparent condition against those from the non-transparent aware condition.

* $\mathrm{p}<0.05$.

Despite the clear pattern regarding the impact of transparency on policy compliance, we did not find support for the explanatory role of trustworthiness. Though the effect of our manipulation on trustworthiness pointed in the expected direction, this effect did not reach conventional levels of significance. Before rejecting the explanation, however, it appeared worthwhile to scrutinize the scale properties with regard to both reliability and construct validity. Indeed, a closer look at the trustworthiness scale showed that the item structure did not replicate the original one, rendering the aggregation into subscales as doubtful. Looking at the individual item level, it became apparent that the participants in the non-transparent conditions agreed less that the university administration approached them in a sincere way $(\mathrm{M}=3.55, \mathrm{SD}=0.82)$ than those in the transparent condition $(\mathrm{M}=3.80, \mathrm{SD}=0.75) ; \mathrm{t}=-2.28, \mathrm{p}=$ 0.023 . This suggests that, without explicit disclosure, defaults might indeed be interpreted as acts of insincerity. In turn, this could elicit a feeling of being deceived and account for the lower compliance rates among the participants in the non-transparent conditions. Insights from the field of communication seem to back up such an assumption. In general, people have specific expectations about the provision of information (Grice, 1989, McCornack, 1992). These include expectations regarding the amount of information that should be provided in a communicative attempt. When such expectations are not met, people may assume that the communicator is withholding information, which can be interpreted as deception (McCornack et al., 1992). When people think they are being deceived, a range of negative reactions, from disappointment to outrage, is typical (Gordon \& Miller, 2000).

Attending to these considerations, we ran a replication study in which we replaced the trustworthiness scale with a specific measure of the subjective feeling of being deceived. Thus, we aimed to capture the role of feeling deceived as a potential mediator of the transparency effect. 


\section{Study 2}

Study 2 aimed at replicating the findings from Study 1. The design and materials were to be the same as those of Study 1, except for small changes to the measurement level. Specifically, the more general trustworthiness measure was replaced with an explicit measure of feeling deceived. In order to improve the external validity of our results, we conducted the experiment with a German-speaking sample.

\section{Method}

\section{Participants}

We extrapolated the required number of participants based on the effect size from the first study. An observed OR of 0.484 and a probability of opt out under transparency of 0.376 rendered a required sample of 294 participants.

Two-hundred and eighty-five participants ( 225 females, 58 males, 2 unclassified) were recruited online via a popular social network. The mean age of the participants was 24.9 years $(\mathrm{SD}=6.03)$. After participation, respondents indicated whether they wanted to be entered into a raffle for two online shopping vouchers of a total value of $€ 30$. After the data collection period expired, two participants were selected at random to receive the vouchers.

\section{Measures}

The presented scenarios and disclosure information were identical to those in Study 1 . After the decision to change the electives or stay with the pre-selected ones, the participants were presented with a self-constructed scale intended to measure the subjective feeling of being deceived. It consisted of three positively phrased items (e.g., "Thinking of my interaction with the university administration at Albington, I believe they approached me in a sincere way") and four negatively phrased items (e.g., "Thinking of my interaction with the university administration at Albington, I believe they tried to trick me"). For all items, see Appendix 2. Participants indicated their agreement with the statements on a seven-point rating scale ( $1=$ "not at all"; $7=$ "most definitely"). The resulting scale had a very high internal consistency (Cronbach's $\alpha=0.89$ ).

Finally, we assessed whether the participants had read and understood the stimulus materials. For an objective and reliable measure of stimulus comprehension, we used a multiple-choice test instead of an open-text format. For a complete list of questions per condition, see Appendix 3. Correct responses on all questions were required in order to include a participant in the analysis. 


\section{Results and discussion}

Forty-eight participants were excluded for providing wrong answers to one or more items of the stimulus material attention check. As can be seen in Table 3, the resulting pattern replicated the findings of Study 1. Again, disclosure decreased opt-out rates, whereas the two non-disclosure conditions did not differ from each other.

The significance of the pattern was tested by means of a binomial logistic regression. The binary decision ( stay $=0$; opt out $=1$ ) was predicted from the same two Helmert contrasts used in our Study 1. The first contrast accounted for differences between the non-transparent groups (non-transparent and nontransparent aware $=-0.33$ ) and the transparency group (transparent $=0.67$ ), indicating how transparency affects opt-out rates. The second Helmert contrast (adjusted for group size) accounted for differences between the two non-transparent groups (non-transparent $=-0.55$, transparent $=0$, non-transparent aware $=0.45$ ). This coefficient indicated whether default awareness leads to greater or fewer opt-out decisions as compared to the non-transparent control group.

In line with the results from our first experiment, the participants in the transparency condition were significantly less likely to opt out, $b=-0.634$ $(\mathrm{SE}=0.301)$, Wald $\chi^{2}(1)=4.43, \mathrm{p}=0.035$, than those in the non-transparent conditions. As expected, the second planned contrast (non-transparent versus non-transparent aware condition) revealed no significant differences between groups, $b=-0.236$ ( $\mathrm{SE}=0.391)$, Wald $-\chi^{2}(1)=0.366, \mathrm{p}=0.545$. A summary of the logistic regression coefficients is presented in Table 4.

As demonstrated in Table 5, the participants' scores of feeling deceived were lowest in the transparent condition, whereas they were almost identical in the non-transparent conditions. To check the significance of the pattern, we regressed the participants' deception scores on the two Helmert contrasts. As expected, the participants in the transparent condition felt significantly less deceived and manipulated than those in the non-transparent groups, $b=$ -0.332 ( $\mathrm{SE}=0.138$ ), $\mathrm{p}=0.017,95 \% \mathrm{CI}-0.604$ to -0.061 . Participants who imagined having discerned all of the default information by themselves did not feel more or less manipulated than those in the other non-transparent condition, $\mathrm{b}=0.077$ ( $\mathrm{SE}=0.163), \mathrm{p}=0.63,95 \% \mathrm{CI}-0.244$ to 0.398 .

Next, we tested whether the subjective feeling of being deceived mediated the effect of transparency on policy compliance. For that purpose, we used four binomial regression models and the SPSS PROCESS macro (Hayes, 2013). The first model indicated that transparency was significantly negatively related to opting out, $\mathrm{b}=-0.634(\mathrm{SE}=0.312), \mathrm{p}=0.032,95 \% \mathrm{CI}-1.261$ to -0.042 . The second demonstrated that transparency led to a decrease in the 
Table 3. Proportion of participants deciding to opt out per condition in Study 2

\begin{tabular}{lccc}
\hline \hline Condition & Transparent & Non-transparent & Non-transparent aware \\
\hline Opt out & $65 \%(54 / 83)$ & $80 \%(60 / 75)$ & $75.9 \%(60 / 79)$ \\
\hline \hline
\end{tabular}

Note: Participants' opt out to stay with default option ratios are in parentheses.

Table 4. Summary of logistic regression analysis for the effects of transparency and awareness on opt-out rates in Study 2

\begin{tabular}{lccccr}
\hline \hline Predictor & $\mathrm{b}$ & $\mathrm{SE}$ & Wald- $\chi^{2}$ & $\mathrm{df}$ & $\mathrm{Exp}(\mathrm{b})$ \\
\hline Transparency & $-0.634^{*}$ & 0.301 & 4.43 & 1 & 0.530 \\
Awareness & -0.236 & 0.391 & 0.366 & 1 & 0.789 \\
Constant & 1.308 & 0.150 & 47.7 & 1 & 2.823 \\
\hline \hline
\end{tabular}

Note: The predictors are weighted Helmert contrasts. Transparency compares participants from the transparent condition versus participants from the other two conditions. Awareness compares participants from the non-transparent condition against those from the non-transparent aware condition.

$* \mathrm{p}<0.05$.

Table 5. Mean scores of feeling deceived per condition in Study 2

\begin{tabular}{lccc}
\hline \hline Condition & Transparent & Non-transparent & Non-transparent aware \\
\hline Feeling deceived & $3.01(-1.23)$ & $3.35(-1.2)$ & $3.44(-1.13)$ \\
\hline \hline
\end{tabular}

Note: Standard deviations are in parentheses.

subjective feeling of being deceived, $\mathrm{b}=-0.332(\mathrm{SE}=0.137), \mathrm{p}=0.017,95 \% \mathrm{CI}$ -0.604 to -0.061 . In turn, feeling deceived accounted for an increase in opt-out rates, $b=0.464(\mathrm{SE}=0.166), \mathrm{p}=0.005,95 \% \mathrm{CI} 0.138-0.791$. Lastly, when the subjective feeling of being deceived and transparency were pooled together in a regression model, the relationship between transparency and opt-out rates was no longer significant, $b=-0.497(\mathrm{SE}=0.310), \mathrm{p}=0.108,95 \% \mathrm{CI}-1.106$ to 0.111. Bootstrap CIs derived from 5000 replicates also demonstrated that the indirect effect coefficient was substantial (the confidence interval does not include 0$), b=-0.154$ ( $\mathrm{SE}=0.082$ ), $95 \% \mathrm{CI}-0.362$ to -0.033 , which supports the hypothesis that the relationship between transparency and opt-out rates is mediated by the subjective feeling of being deceived. 
As previously stated, the results show that institutions can increase policy compliance by making default manipulations transparent. Importantly, disclosure by an endorser safeguards against people becoming suspicious or feeling manipulated, which in turn makes them more likely to comply with the default.

Despite the clear evidence for a beneficial effect of transparency on default compliance, limitations may arise from the fact that the choices in our setup were hypothetical. Although using scenarios is a common approach to assessing transparency effects (Loewenstein et al., 2015, Steffel et al., 2016, studies 2 and 3), it cannot be guaranteed that effects for hypothetical choices will be observed for actual choices as well. In fact, recent research in a different hypothetical setting showed that transparency may lead to more positive attitudes toward the default-setter, but these effects do not necessarily transfer to default compliance (Steffel et al., 2016). In order to test whether transparency effects on compliance rates are evident in actual choice behavior, we conducted a third experimental study.

\section{Study 3}

As in the previous studies, the moderating role of transparency on default compliance was tested in a university decision context, but with actual choices. Participants chose between several studies in which they could volunteer to participate. The studies were described in terms of their different durations. Analogously to the previous studies, we presented transparent and non-transparent default conditions in both of which the middle study duration (8-10 minutes) was pre-selected. Differently from the previous studies, we also ran a free-choice (non-default) condition in order to isolate a default effect and possible participant preferences for the middle study duration.

\section{Method}

\section{Participants}

A convenience sample of 179 participants (131 females, 47 males, 1 unclassified) was obtained via a popular social network. The mean age of the participants was 25.8 years $(S D=7.03)$. They were randomly assigned to one of the three between-participant conditions (transparent default vs. non-transparent default vs. free choice). A subsequent sensitivity analysis revealed that given $n=179,1-\beta=0.8, \alpha=0.05$ and an observed $\operatorname{Pr}(\mathrm{Y}=1 \mid \mathrm{X}=1) \mathrm{H} 0=0.46$, our study was sufficiently sensitive to detect a minimum effect size (OR) of 2.132.

After participation, respondents indicated whether they wanted to be entered into a raffle for two online shopping vouchers with a total value of $€ 20$. After 
the data collection period expired, two participants were selected at random to receive the vouchers.

\section{Materials and procedure}

On a social media platform, an invitation to participate in psychological research was posted and the respective link was provided. Participants who clicked on the link were informed that there were several studies from which they could choose and that the studies differed in content and duration. Only the duration was provided for each study without further content description. Participants were also informed that the reward for their participation was independent of the duration of the study they chose to complete. The following five choice options were listed: " $<5$ minutes," "5-8 minutes," " $8-10$ minutes," "10-12 minutes" and "more than 12 minutes." In both default conditions, the middle "8-10 minutes" study duration category was pre-selected. In the transparent condition, the pre-selection was accompanied by a notification explaining the purpose and the behavioral means of the pre-selection (the full text of the stimulus material per condition is available in Appendix 4). In a free-choice condition, none of the options was pre-selected. In order to preserve the participants' time resources, no actual study was administered. Upon indicating their choice, all respondents were redirected to a page where they were thoroughly debriefed about the procedure and purpose of the experiment, and where they could participate in the prize raffle.

\section{Results and discussion}

Descriptive results are reported in Table 6. In the transparent condition, 46.6\% of the participants chose to stay with the default (vs. $53.4 \%$ who opted out), while in the non-transparent default condition, only $27.1 \%$ chose this option, but $72.9 \%$ opted out. For a comparison standard, the crucial option was selected by only $11.3 \%$ of the participants in the free-choice condition.

For a test of significance, choices (coded $0=$ stay/middle option; $1=$ opt out/ other option) were predicted from two Helmert contrasts in a binomial logistic regression. The contrasts indicated whether there was a default or not (transparent default and non-transparent default $=0.33$; free choice $=-0.67$ ) and whether the default was transparent or not (transparent default $=0.50$, free choice $=0$, non-transparent default $=-0.50)$. A summary of the coefficients is available in Table 7.

The first contrast was significant, $b=1.498(\mathrm{SE}=0.446)$, Wald $-\chi^{2}(1)=$ $11.23, \mathrm{p}=0.001$, showing that defaults systematically increase the choice of the pre-selected option over a free-choice format. Pertinent to our research question, transparency significantly increased the proportion of participants 
Table 6. Percentages of decisions to stay versus opt out from designated option per condition in Study 3

\begin{tabular}{lccc}
\hline \hline Condition & Transparent default & Non-transparent default & Free choice \\
\hline Stay & $46.6 \%(27 / 58)$ & $27.1 \%(16 / 59)$ & $11.3 \%(7 / 62)$ \\
Opt out & $54.3 \%(41 / 58)$ & $72.9 \%(43 / 59)$ & $88.7 \%(55 / 62)$
\end{tabular}

Note: Proportion of participants who chose the option pre-selected in the default conditions (upper row) vs. proportion of participants who chose an alternative option (lower row).

Table 7. Summary of logistic regression analysis for the effects of default and transparency on choice in Study 3

\begin{tabular}{lccccc}
\hline \hline Predictor & $\mathrm{b}$ & $\mathrm{SE}$ & Wald- $\chi^{2}$ & $\mathrm{df}$ & $\mathrm{Exp}(\mathrm{b})$ \\
\hline Default & $1.498^{* *}$ & 0.446 & 11.231 & 1 & 4.472 \\
Transparency & $0.85^{*}$ & 0.393 & 4.664 & 1 & 2.34 \\
Constant & -1.058 & 0.186 & 32.022 & 1 & 0.347 \\
\hline
\end{tabular}

Note: The predictors are Helmert contrasts. Default compares participants from the default conditions versus participants from the free choice condition. Transparency compares participants from the non-transparent default condition against those from the transparent default condition.

*p $<0.05 ; *$ p $<0.01$.

choosing the defaulted option as compared to the non-transparent default condition: $\mathrm{b}=0.850(\mathrm{SE}=0.393)$, Wald $-\chi^{2}(1)=32.02, \mathrm{p}=0.031$. Thus, even in case of actual choices, making a default transparent increased its efficiency. It should be noted that the respective option was not highly favored a priori. The default setting more than doubled choices for this option, and making the defaulting strategy transparent quadrupled it.

\section{General discussion}

Across three experiments, we demonstrated that the full disclosure of a default's presence, purpose and behavioral means increased policy compliance. Notably, this was the case for hypothetical as well as for actual choices. Such a finding supports the call for transparency in nudging interventions (Sunstein, 2015), showing that a transparent default may still be effective.

Our data also suggest that, to some extent, people may feel deceived when a default is presented, no matter whether they manage to retrieve all defaultrelated information or not. A full disclosure by the endorser is a possible 
remedy against such inferences. In a broader sense, such a finding lends support to the proactive disclosure perspective in governance (Darbishire, 2010) and shows that proactive transparency can be a beneficial tool for increasing policy compliance in cases where the traditional (i.e., reactive) open-access approaches fail.

While these findings advocate transparency as a tool to increase default efficacy, there are some limitations to their generalizability. First, transparency may not always yield the inference that the endorser is fair. For instance, we would expect that disclosure effects depend on whether the disclosure is perceived as being voluntarily made. If one perceives the disclosure as being given by obligation (e.g., due to a specific regulation that requires it), the introduction of transparency may lose its advantage. Second, transparency effects should depend on whether the purpose is compatible with the receiver's interest. That is, receivers might be willing to comply with defaults that serve themselves or an institution they are willing to support. Disclosing that the default serves the default-setter's vested self-interests at the cost of the receiver may yield smaller if not detrimental effects (cf. Steffel et al., 2016). Likewise, transparency may not increase default compliance if it discloses unacceptable costs. Bruns et al. (2018) studied default effects on donation behavior and did not find an advantage of transparency. Different from the present study, however, defaults in Bruns et al. (2018) were set to a very costly option (i.e., donate $80 \%$ of the money earned). Arguably, transparency affects the willingness to comply, but only within the personal latitude of acceptance. Taken together, these considerations might imply that transparency is most beneficial for defaults nudging people to the better - which is a basic requirement in the nudging paradigm.

However, this does not exclude the possibility of a detrimental effect of endorser disclosure on the effectiveness of non-transparent nudges in general (cf. Bovens, 2009). Behavioral interventions that directly influence the attributes of our choice alternatives (e.g., decreasing portions or plate sizes in cafeterias) are much more difficult to detect, and can thus be perceived as more intrusive when disclosed. Perhaps such interventions would still work best in the dark, but this remains to be seen.

\section{Conclusion}

In summary, the present research adds to the available literature on default effects and demonstrates that default-based policies can be both ethical and effective at the same time. In doing so, it contributes to the ongoing ethicality-effectiveness debate, showing that, at least in some situations, one can have the best of both worlds: an ethical and effective behavioral intervention. 


\section{Acknowledgments}

The authors want to thank Prof. Dr. Edgar Erdfelder for comments on the a priori power analysis. They also thank Mr. Moritz Ingendahl for the technical implementation of the online studies.

\section{References}

Allcott, H. and S. Mullainathan (2010), 'Behavior and energy policy', Science, 327(5970): 1204 1205.

Brehm, J.W. (1966), A theory of psychological reactance, Oxford: Academic Press

Bruns, H., E. Kantorowicz-Reznichenko, K. Klement, M.L. Jonsson and B. Rahali (2018), 'Can nudges be transparent and yet effective?', Journal of Economic Psychology, 65: 41-59.

Bovens, L. (2009), 'The ethics of nudge', In T. Grüne-Yanoff and S.O. Hansson (eds), Preference change, Dordrecht: Springer.

Darbishire, H. (2010), Proactive Transparency: The future of the right to information?, New York: World Bank

Deci, E. L. (1975), Intrinsic motivation, New York: Plenum.

Falk, A. and F. Zimmerman (2013), 'A taste for consistency and survey response behavior', CESifo Economic Studies, 59: 181-193.

Faul, F., E. Erdfelder, A. Buchner and A.G. Lang (2009), 'Statistical power analyses using G*Power 3.1: Tests for correlation and regression analyses', Behavior Research Methods, 41: 1149-1160.

Grice, H. P. (1989), Studies in the Way of Words, Harvard University Press.

Grimmelikhuijsen, S.G. and A.J. Meijer (2012), 'Effects of transparency on the perceived trustworthiness of a government organization: Evidence from an online experiment', Journal of Public Administration Research and Theory, 24(1): 137-157.

Gordon, A. K. and A. G. Miller (2000), 'Perspective differences in the construal of lies: Is deception in the eye of the beholder?', Personality and Social Psychology Bulletin, 26(1): 46-55.

Hansen, P. G. and A. M. Jespersen (2013), 'Nudge and the manipulation of choice: A framework for the responsible use of the nudge approach to behavior change in public policy', European Journal of Risk Regulation, 4(1): 3-28.

Hayes, A.F. (2013), Introduction to Mediation, Moderation, and Conditional Process Analysis: A Regression-Based Approach. New York: The Guilford Press.

Johnson, E.J. and D. Goldstein (2003), 'Do defaults save lives?', Science, 302: 1338-1339.

Kinney, A. Y., C. Richards, S.W. Vernon and V.G. Vogel (1998), 'The effect of physician recommendation on enrollment in the breast cancer chemoprevention trial', Preventative Medicine, 27(1): 713-719.

Loewenstein, G., C. Bryce, D. Hagmann and S. Rajpal (2015), 'Warning: You are about to be nudged', Behavioral Science \& Policy, 1(1): 35-42.

McCornack, S. A. (1992), 'Information manipulation theory', Communications Monographs, 59(1): $1-16$.

McCornack, S. A., T. R. Levine, K. A. Solowczuk, H. I. Torres and D. M. Campbell (1992), 'When the alteration of information is viewed as deception: An empirical test of information manipulation theory', Communications Monographs, 59(1): 17-29.

McKenzie, C. R., M. J. Liersch and S. R. Finkelstein (2006), 'Recommendations implicit in policy defaults', Psychological Science, 17(5): 414-420.

Park, H., and J. Blenkinsopp (2011), 'The roles of transparency and trust in the relationship between corruption and citizen satisfaction', International Review of Administrative Sciences, 77(2): $254-274$. 
Ryan, R. M. and E. L Deci (2000), 'Self-determination theory and the facilitation of intrinsic motivation, social development, and well-being', American Psychologist, 55(1): 68-78.

Smith, N. C., D. G. Goldstein and E. J. Johnson (2012), 'Choice without awareness: Ethical and policy implications of defaults', Journal of Public Policy \& Marketing, 32(2): 159-172.

Steffel, M., E. F. Williams and R. Pogacar (2016), 'Ethically deployed defaults: transparency and consumer protection through disclosure and preference articulation', Journal of Marketing Research, 53(5): 865-880.

Sunstein, C. R. (2015), Nudging and Choice Architecture: Ethical Considerations. Yale Journal on Regulation, Forthcoming. Available at SSRN: https://ssrn.com/abstract=2551264

Thaler, R. H. and S. Benartzi (2004), 'Save more tomorrow ${ }^{\mathrm{TM}}$ : Using behavioral economics to increase employee saving', Journal of political Economy, 112(S1): S164-S187.

Tyler, T. R. (1990), Why People Obey The Law, New Haven: Yale University Press.

Tyler, T. R. (1998), 'Trust and democratic governance', Trust and governance, 1: 269.

Walster, E., E. Aronson and D. Abrahams (1966), 'On increasing the persuasiveness of a low prestige communicator', Journal of Experimental Social Psychology, 2(4): 325-342.

Willis, L.E. (2013), 'When nudges fail: Slippery defaults', The University of Chicago Law Review, 80 (3): 1155-1229.

\section{Appendix 1}

\section{Stimulus Material Studies 1 and 2 per condition}

\section{Non-transparent condition}

Please read the text below carefully and answer the question honestly. There is no right or wrong answer, just pick the answer you want. Once you are ready, please click the 'Next' button.

Shortly after finishing your bachelor studies, you find a suitable master's program at another university. Not before long, you get accepted and move to campus. As soon as you get your online university credentials, you browse through the courses, included in the program. You notice that besides being enrolled in the mandatory courses, you have also been registered for a few elective ones.

The electives you are registered for vary in content and length.

Underneath the elective course descriptions you see the following information:

Please note, that you can change the pre-selected electives to other alternatives. In order to do so, you can visit the administration department and file a change form (available in hard copy only).

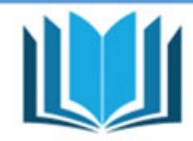

ALBINGTON UNIVERSITY

What do you do next?

Stay with the pre-selected courses

Change the pre-selected courses to the other alternatives 


\section{Transparent condition}

Please read the text below carefully and answer the question honestly. There is no right or wrong answer, just pick the answer you want. Once you are ready, please click the 'Next' button.

Shortly after finishing your bachelor studies, you find a suitable master's program at another university. Not before long, you get accepted and move to campus. As soon as you get your online university credentials, you browse through the courses, included in the program. You notice that besides being enrolled in the mandatory courses, you have also been registered for a few elective ones.

The electives you are registered for vary in content and length.

Underneath the elective course descriptions you see the following information:

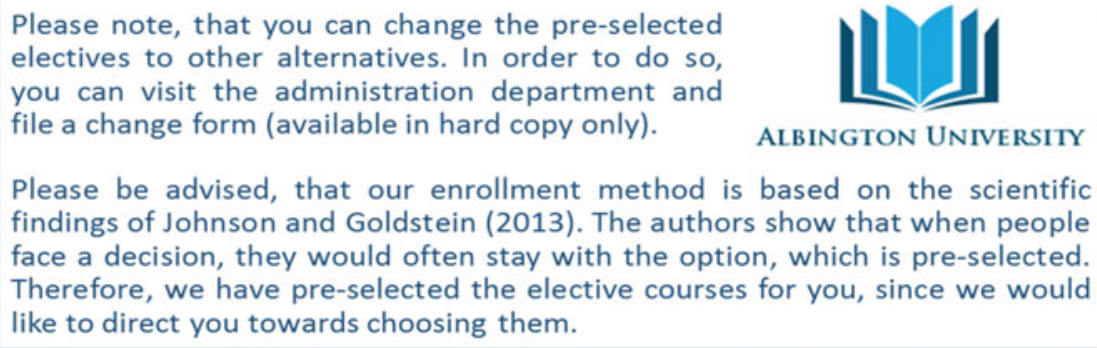

Please note, that you can change the pre-selected electives to other alternatives. In order to do so, you can visit the administration department and file a change form (available in hard copy only).

ALBINGTON UNIVERSITY

Please be advised, that our enrollment method is based on the scientific findings of Johnson and Goldstein (2013). The authors show that when people face a decision, they would often stay with the option, which is pre-selected. Therefore, we have pre-selected the elective courses for you, since we would like to direct you towards choosing them.

What do you do next?

Stay with the pre-selected courses

Change the pre-selected courses to the other alternatives

\section{Non-transparent aware condition}

Please read the text below carefully and answer the question honestly. There is no right or wrong answer, just pick the answer you want. Once you are ready, please click the 'Next' button.

Shortly after finishing your bachelor studies, you find a suitable master's program at another university. Not before long, you get accepted and move to campus. As soon as you get your online university credentials, you browse through the courses, included in the program. You notice that besides being enrolled in the mandatory courses, you have also been registered for a few elective ones.

The electives you are registered for vary in content and length.

Underneath the elective course descriptions you see the following information: 
Please note, that you can change the pre-selected electives to other alternatives. In order to do so, you can visit the administration department and file a change form (available in hard copy only).

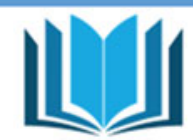

ALBINGTON UNIVERSITY

You remember that you recently stumbled over a scientific article by Johnson and Goldstein (2003). The authors showed that when people face a decision, they would often stay with the option which is pre-selected. Thus, you infer that the university administration has pre-selected the elective courses for you, since they want to direct you towards choosing them.

What do you do next?

O Change the pre-selected courses to the other alternatives

O Stay with the pre-selected courses

\section{Appendix 2}

Subjective feeling of being deceived measure (Cronbach's $\alpha=0.89$ )

Participants indicated their agreement with seven statements on a seven-point Likert scale, anchored from 1 (not at all) to 7 (most definitely). Three of the items were positively worded and their scores consequently reversed.

Thinking of my interaction with the university administration at Albington, I believe they...

Were open with me..........................not at all (1) most definitely (7)

Tried to trick me.............................not at all (1) most definitely (7)

Approached me in a sincere way................not at all (1) most definitely (7)

Made an attempt to swindle me...................not at all (1) most definitely (7)

Were trying to mislead me......................not at all (1) most definitely (7)

Were honest with me..........................not at all (1) most definitely (7)

\section{Appendix 3}

Control questions study 2 (per condition)

Non-transparent condition

Please, answer the following questions about the situation you were confronted with in the beginning:

In the presented situation, we asked you to imagine, that...

- You were a teacher in a foreign university

- You recently paid a high tuition fee in a university

- You enrolled in a master's program 
When you had a look at the courses you needed to follow...

- You had to choose all your elective courses by yourself

- Some of the elective courses were already chosen for you

- Some of the elective courses were past deadline for enrollment

A university disclaimer underneath the course descriptions stated that...

- You can change the preselected electives after you hand in a change form in person

- You cannot change the preselected electives

- You can change the preselected electives online

\section{Non-transparent aware condition}

The three questions from the non-transparent condition plus:

After you read about the enrollment procedure at Albington, you remembered about an article, which explains

- That when people face a decision, they will often stay with the option, which is preselected for them

- That when people face a decision, they will often select the option, which is best for them

- That when people face a decision, they will often postpone their choice for a later time

Based on the information in the article you remembered reading, you inferred that...

- The university administration preselected the elective courses for you, since they wanted you to make an active choice

- The university administration preselected the elective courses for you by mistake

- The university administration preselected the elective courses for you, since they wanted you to stick with these courses

\section{Transparent condition}

The three questions from the non-transparent condition plus:

The university administration at Albington posted a disclaimer, which contained information about their enrollment policy. What was their enrollment policy based on?

- On the fact, that when people face a decision, they will often stay with the option, which is preselected for them

- On the fact, that when people face a decision, they will often select the best option for them 
- On the fact, that when people face a decision, they will often postpone their decision for a later time

\section{Appendix 4}

\section{Stimulus Material Study 3 per condition}

Transparent default condition

Welcome to the experimental database of the Department of Economic and Consumer Psychology.

We have a large selection of studies that you can work on. The studies have different content and duration.

Please select a category of studies from the options below. The categories are ordered according to the duration of the studies they contain. Once you have selected a category, you will be randomly assigned a study of the respective duration.

Please note the following: based on the results of Johnson und Goldstein (2003) we know that in decision situations, people often stick with a choice option, which is preselected for them. Therefore, we have preselected a category for you, since we would want you to choose a study from this category.

Once you have completed the study, you can enter a raffle to win two $€ 10$ Amazon vouchers. Please note that you will only receive one entry, no matter if you have completed a long or a short study.
Category A $(<5$ minutes)
Category B (5-8 minutes)
- Category C (8-10 minutes)
C Category D (10-12 minutes)
C Category E (>12 minutes)

\section{Default condition}

Welcome to the experimental database of the Department of Economic and Consumer Psychology.

We have a large selection of studies that you can work on. The studies have different content and duration. 
Please select a category of studies from the options below. The categories are ordered according to the duration of the studies they contain. Once you have selected a category, you will be randomly assigned a study of the respective duration.

Once you have completed the study, you can enter a raffle to win two $€ 10$ Amazon vouchers. Please note that you will only receive one entry, no matter if you have completed a long or a short study.

Category A ( $<5$ minutes)

Category B (5-8 minutes)

- Category C (8-10 minutes)

C Category D (10-12 minutes)

C Category E ( $>12$ minutes)

Free choice condition

Welcome to the experimental database of the Department of Economic and Consumer Psychology

We have a large selection of studies that you can work on. The studies have different content and duration.

Please select a category of studies from the options below. The categories are ordered according to the duration of the studies they contain. Once you have selected a category, you will be randomly assigned a study of the respective duration.

Once you have completed the study, you can enter a raffle to win two $€ 10$ Amazon vouchers. Please note that you will only receive one entry, no matter if you have completed a long or a short study.

Category A ( $<5 \mathrm{~min})$

C Category B (5-8 min)

C Category C (8-10 min)

Category D (10-12 min)

C Category E ( $>12 \mathrm{~min})$ 